\title{
Technics Research on Polycrystalline Cubic Boron Nitride Cutting Tools Dry Turning Ti-6AL- 4V Alloy Based on Orthogonal Experimental Design
}

\author{
Yunhai $\mathrm{Jia}^{1,2}{ }^{*}$, Lixin $\mathrm{Zhu}^{2}$ \\ ${ }^{1}$ Beijing Institute of Electro-machining, 100191 Beijing, China \\ ${ }^{2}$ Beijing Key Laboratory of Electrical Discharge Machining Technology, 100191 Beijing, China
}

\begin{abstract}
Ti-6Al-4V components are the most widely used titanium alloy products not only in the aerospace industry, but also for bio-medical applications. The machine-ability of titanium alloys is impaired by their high temperature chemical reactivity, low thermal conductivity and low modulus of elasticity. Polycrystalline cubic boron nitride represents a substitute tool material for turning titanium alloys due to its high hardness, wear resistance, thermal stability and hot red hardness. For determination of suitable cutting parameters in dry turning Ti-6AL-4V alloy by Polycrystalline cubic boron nitride cutting tools, the samples, $300 \mathrm{~mm}$ in length and $100 \mathrm{~mm}$ in diameter, were dry machined in a lathe. The turning suitable parameters, such as cutting speed, feed rate and cut depth were determined according to workpieces surface roughness and tools flank wear based on orthogonal experimental design. The experiment showed that the cutting speed in the range of $160 \sim 180 \mathrm{~m} / \mathrm{min}$, the feed rate is 0.15 $\mathrm{mm} / \mathrm{rev}$ and the depth of cut is $0.20 \mathrm{~mm}$, ideal workpiece surface roughness and little cutting tools flank wear can be obtained.
\end{abstract}

\section{Introduction}

Titanium alloys find wide application in many industries. Titanium after being alloyed with aluminum, vanadium and other elements is highly suitable to be used in aircraft, naval ships, armor plating, missiles and aircrafts, due to their unrivalled and unique combination of high strength-to-weight ratio and high resistance to corrosion. Most importantly, it resists the crack growth and creep elongation even at high temperatures. Ti-6Al-4V is the mostly used alloy in aircraft applications, almost $50 \%$ of all alloys ${ }^{[1,2]}$. The machinability of titanium alloys is impaired by their high temperature chemical reactivity, low thermal conductivity and low modulus of elasticity ${ }^{[3]}$. The machine-ability of Ti-6Al-4V has been investigated actively worldwide since 1980 s and most researchers have found that polycrystalline cubic boron nitride $(\mathrm{PcBN})$ and polycrystalline diamond (PCD) tools can be used to machine Ti$6 \mathrm{Al}-4 \mathrm{~V}$ effectively ${ }^{[4]}$. The development of new tool materials in the past ten years, such as

\footnotetext{
*Corresponding author: jyh308401@sina.com.cn
} 
Polycrystalline cubic Boron Nitride (PcBN), makes precision hard turning possible, in which the hardness of the workpiece is up to 58-62 $\mathrm{HRC}^{[5]}$. Parts with hardness exceeding 45 HRC can be machined by hard turning, which provides surface roughness, dimensional and shape tolerances similar to those achieved in grinding. The grinding process, of surface finishing, is now replaced by the hard turning as it owns some of the benefits ${ }^{[6]}$, i.e., capability to produce, complex parts, reduced cycle time, low cost, higher productivity, etc. PcBN (polycrystalline cubic boron nitride) is the material most commonly used in tools for hardened steel turning applications due to its high hardness, wear resistance and thermal stability ${ }^{[5]}$.

There have been many valuable research results from Ti-6AL-4V alloy machining. Bouacha et al. optimized hard turning operation in respect of cutting speed, feed rate, depth of cut and machining time. The tool wear, surface roughness, cutting forces, and metal volume removed were the responses. The cutting speed and feed rate were the most significant factors for surface roughness; specifically, the higher cutting speed produced a better surface finish ${ }^{[7]}$. In DA Fadare study, the steepest descent method was used to study the effects of cutting parameters on surface roughness of machined Ti-6Al-4V alloy workpiece at high-speed conditions. The results revealed that surface roughness was more sensitive to variation in feed rate followed by cutting speed and depth of cut ${ }^{[8]}$. SK Goyal et al analyze the performance of precision turning using conventional lathe on Ti6Al4V under dry working conditions. Various parameters that affect the machining processes were identified and a consensus was reached regarding its values ${ }^{[9]}$. In ZQ Liu study, the cutting forces and roughness for turned surfaces were measured and analyzed by using singlefactor turning experiments. They pointed that PcBN tools at the cutting conditions of higher cutting speed, lower feed rate and lower depth of cut have a longer tool life, lower cutting force, better surface roughness, which means that $\mathrm{PcBN}$ tools are adapted in precision processes of machining the titanium alloy TC4 ${ }^{[10]}$.

The aim of this investigation was to study the suitable turning parameters, such as cutting speed $(v)$, feed rate $(f)$ and depth of cut $\left(a_{p}\right)$, which were determined according to workpieces surface roughness $\left(W_{R a}\right)$, average cutting tool flank wear $(V B)$ when using PcBN cutting tools dry turning Ti-6AL-4V alloy.

\section{Experimental equipment and method}

Workpiece materials selected for investigation were the Ti-6AL-4V alloy rod with the composition given in Table 1. The size of the workpiece used for experimentation was round rods with dimension $100 \mathrm{~mm}$ diameter and $300 \mathrm{~mm}$ long. The physical and mechanical properties of the Ti-6AL-4V alloy were listed in Table 2. They were machined by Polycrystalline cubic Boron Nitride cutting tools (BZN 9100 produced by DI Corporation) in dry turning in a lathe (CAK6150). The cutting tool geometry parameters were shown in Table 3. The TR240 surface roughness tester, 19JPC-V universal tool maker's microscope and S-4800 scanning electron microscope (SEM) are selected as experimental analyzer.

Table 1. Composition of workpiece $(\Phi 100 \times 300 \mathrm{~mm})$ material $(\%)$.

\begin{tabular}{|c|c|c|c|c|c|c|c|c|c|}
\hline Workpiece material & $\mathbf{C}$ & $\mathbf{A L}$ & $\mathbf{V}$ & $\mathbf{S i}$ & $\mathbf{F e}$ & $\mathbf{N}$ & $\mathbf{H}$ & $\mathbf{O}$ & $\mathbf{T i}$ \\
\hline Ti-6AL-4V & 0.1 & 6.2 & 4 & 0.15 & $\leqslant 0.25$ & 0.05 & 0.0125 & $\leqslant 0.2$ & Others \\
\hline
\end{tabular}


Table 2. Physical and mechanical properties of the Ti-6AL-4V alloy.

\begin{tabular}{|c|c|c|c|c|c|c|c|}
\hline $\begin{array}{l}\text { Density } \\
\left(\mathrm{g} / \mathrm{cm}^{3}\right)\end{array}$ & $\begin{array}{c}\text { Melting } \\
\text { point } \\
\left({ }^{\circ} \mathrm{C}\right)\end{array}$ & $\begin{array}{c}\text { Specific } \\
\text { heat } \\
\text { capacity } \\
\left(\mathrm{J} / \mathrm{Kg}{ }^{\circ} \mathrm{C}\right)\end{array}$ & $\begin{array}{c}\text { Thermal } \\
\text { conductivity } \\
(\mathrm{W} / \mathrm{mK})\end{array}$ & $\begin{array}{c}\text { Electric } \\
\text { resistivity } \\
\text { (ohm.cm) }\end{array}$ & $\begin{array}{c}\text { Fracture } \\
\text { Toughness } \\
\left(\text { MPam }^{1 / 2}\right)\end{array}$ & $\begin{array}{c}\text { Elastic } \\
\text { modulus } \\
(\text { GPa) }\end{array}$ & $\begin{array}{c}\text { Hardness } \\
\text { (HRC) }\end{array}$ \\
\hline 4.43 & 1649 & 526.3 & 6.7 & $\begin{array}{c}1.78 \times 10^{-} \\
4\end{array}$ & 75 & 113.8 & 38 \\
\hline
\end{tabular}

Table 3. Cutting tool geometry parameters.

\begin{tabular}{|c|c|c|c|c|c|c|}
\hline $\begin{array}{c}\text { Rake } \\
\text { angle } \\
\gamma_{0}\left({ }^{\circ}\right)\end{array}$ & $\begin{array}{c}\text { Flank } \\
\text { angle } \\
\boldsymbol{\alpha}_{\mathbf{0}}\left({ }^{\circ}\right)\end{array}$ & $\begin{array}{c}\text { Blade } \\
\text { angle } \\
\lambda_{\mathbf{s}}\left({ }^{\circ}\right)\end{array}$ & $\begin{array}{c}\text { Edge } \\
\text { angle } \\
\mathbf{k}_{\mathbf{r}}\left({ }^{\circ}\right)\end{array}$ & $\begin{array}{c}\text { Nose } \\
\text { radial } \mathbf{r}_{\varepsilon} \\
(\mathbf{m m})\end{array}$ & $\begin{array}{c}\text { Vice chamfering } \\
\text { width } \mathbf{b}_{\mathbf{r} 1}(\mathbf{m m})\end{array}$ & $\begin{array}{c}\text { Vice } \\
\text { chamfering } \\
\text { angle } \gamma_{01}\left({ }^{\circ}\right)\end{array}$ \\
\hline 3 & 8 & 0 & 80 & 0.5 & 0.2 & 10 \\
\hline
\end{tabular}

Surface roughness is used as the critical quality indicator for the machined surface. Formation of a rough surface is a complicated mechanism involving many parameters. The quality of the workpiece (either roughness or dimension) is greatly influenced by the cutting conditions, tool geometry, tool material; machining process; workpiece material and tool wear during cutting.

Orthogonal experimental design has been used to analyze relationships between the turning parameters and workpiece surface quality. The combinations of the factors at their different levels and the corresponding measured values of the surface roughness generated after the machining operations are given in Table 4.

Table 4. Orthogonal experimental design and experiment results (continue turning 2 minute).

\begin{tabular}{|c|c|c|c|c|c|}
\hline $\mathbf{S} / \mathbf{N}$ & $\begin{array}{c}\text { Cutting } \\
\mathbf{s p e e d} \\
\mathbf{v}(\mathbf{m} / \mathbf{m i n})\end{array}$ & $\begin{array}{c}\text { Feed rate } \\
\mathbf{f} \\
(\mathbf{m m} / \mathbf{r e v})\end{array}$ & $\begin{array}{c}\text { Depth of cut } \mathbf{a}_{\mathbf{p}} \\
\mathbf{( m m )}\end{array}$ & $\begin{array}{c}\text { Workpiece surface } \\
\left.\text { roughness } \mathbf{W}_{\mathbf{R a}} \mathbf{( u m}\right)\end{array}$ & $\begin{array}{c}\text { Flank face } \\
\text { wear } \\
\text { VB (mm) }\end{array}$ \\
\hline 1 & 120 & 0.10 & 0.15 & 0.45 & 0.012 \\
\hline 2 & 120 & 0.15 & 0.20 & 0.49 & 0.009 \\
\hline 3 & 120 & 0.20 & 0.25 & 0.95 & 0.090 \\
\hline 4 & 160 & 0.10 & 0.20 & 0.39 & 0.011 \\
\hline 5 & 160 & 0.15 & 0.25 & 0.45 & 0.019 \\
\hline 6 & 160 & 0.20 & 0.15 & 0.47 & 0.029 \\
\hline 7 & 200 & 0.10 & 0.25 & 0.60 & 0.035 \\
\hline 8 & 200 & 0.15 & 0.15 & 0.41 & 0.026 \\
\hline 9 & 200 & 0.20 & 0.20 & 0.46 & 0.085 \\
\hline
\end{tabular}

\section{Study on relationship between turning parameters and workpiece surface roughness}

The values of workpiece surface roughness were compared in Fig. 1(a) on the condition of the feed rate of $0.15 \mathrm{~mm} / \mathrm{rev}$, cutting speeds from 80 to $220 \mathrm{~m} / \mathrm{min}$, three different depths of cut $0.15,0.20$ and $0.25 \mathrm{~mm}$. From this figure, it can be known that with increasing of cutting speed, workpiece surface roughness values decreased until a minimum value was reached, after that surface roughness values increased. The lowest average value of workpiece surface roughness got obtained at $180 \mathrm{~m} / \mathrm{min}$ cutting speed. The values of workpiece surface roughness were compared in Fig. 1(b) in the condition of depth of cut 0.20 , feed rate from 0.05 to $0.40 \mathrm{~mm} / \mathrm{rev}$, three different cutting speeds 120,160 and $200 \mathrm{~m} / \mathrm{min}$. 
From this figure, it can be known that with increasing feed rate, workpiece surface roughness values increase. Fig. 1(c) shows the relationship between depths of cut with workpiece surface roughness. It can be seen in this figure that workpiece surface roughness with the increase of cutting depth, slightly reduced then increased, because of the low elastic modulus of titanium alloy, so when the cutting depth is less than $0.05 \mathrm{~mm}$, processing produced the spring-back deformation, so that the processing quality rather than cut deep $0.15 \mathrm{~mm}$. With the further increase of the cutting depth, the dynamic cutting force also increases, which leads to the deformation of the titanium alloy and the vibration of the machining system, and the surface roughness increases.

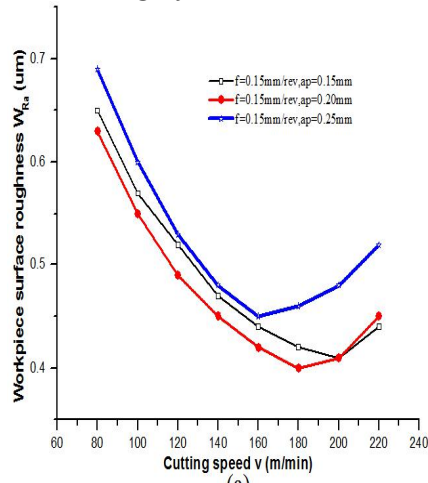

(a)

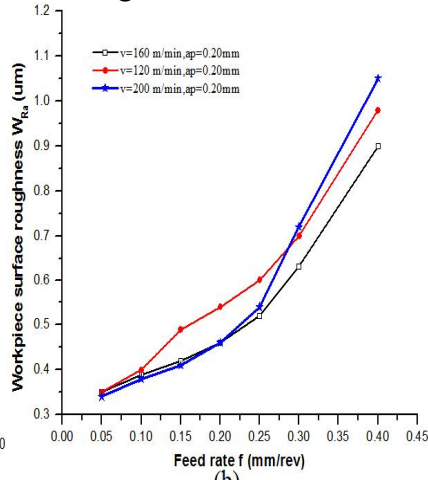

(b)

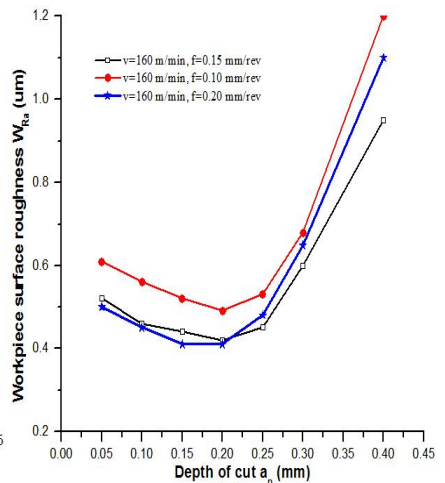

(c)

Fig. 1. Relation curve between turning parameters and workpiece surface roughness.

\section{Research on cutting tool's flank wear}

Fig. 2(a) shows the worn surface of PcBN cutting tools rake face after using PcBN continue dry turning Ti-6AL-4V alloy rod ten minutes. Fig. 2(b) shows the worn surface of PcBN cutting tools flank face after using PcBN continue dry turning Ti-6AL-4V alloy rod ten minutes.

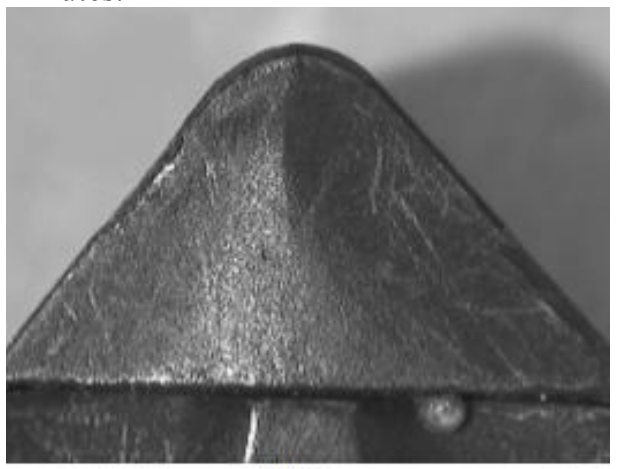

(a)

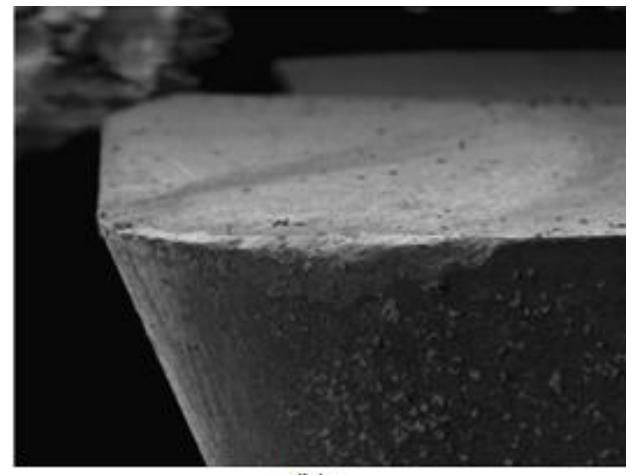

(b)

Fig. 2. SEM of PcBN cutting tools face.

The effects of cutting speed and feed rate values on the cutting tools flank wear were given in Fig. 3(a) and (b). From Fig. 3(a), it can be seen that flank face wear slow vary with the cutting speed increase when cutting speed is below $180 \mathrm{~m} / \mathrm{min}$, after that flank wear huge increase. From Fig. 3(b), it can be seen that flank face wear slow increase in the feed rate increase when the feed rate is below $0.15 \mathrm{~mm} / \mathrm{rev}$, after that flank wear huge increase. 


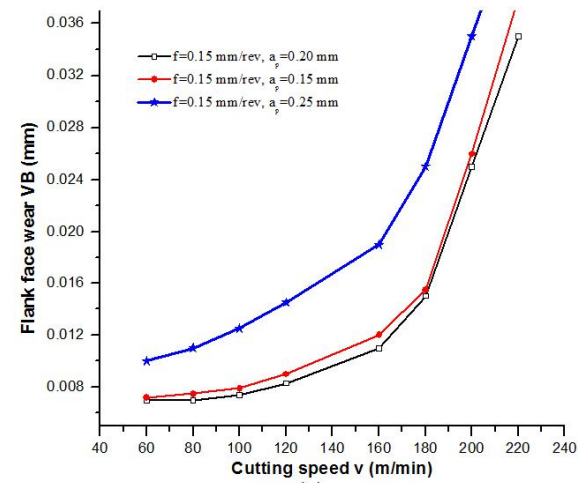

(a)

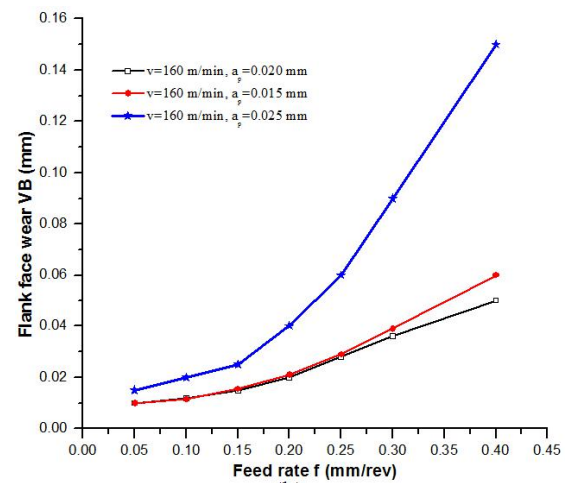

(b)

Fig. 3. Relation curve between turning parameters and cutting tools flank wear.

\section{Conclusions}

Through the test and analysis of the above, the conclusion can be obtained as follow:

(1) The surface roughness was more sensitive to variation in cutting speed than the depth of cut when the feed rate is below $0.20 \mathrm{~mm} / \mathrm{rev}$.

(2) The effect of feed rate and depth of cut on flank wear was higher than that of cutting speed during PcBN cutting tools dry turning Ti-6Al-4V alloy workpiece.

(3) Good surface quality can be achieved at low feed rate and depth of cut with high cutting speed in using PcBN cutting tools dry turning Ti-6Al-4V alloy. It can be obtained ideal workpiece surface roughness and little cutting tools flank face wear, the cutting speed in the range of $160-180 \mathrm{~m} / \mathrm{min}$, the feed rate is $0.15 \mathrm{~mm} / \mathrm{rev}$ and the depth of cut is $0.20 \mathrm{~mm}$.

This lesson is supported by Beijing Natural Science Foundation the Grant No. 3162013 and Beijing Academy of Science and Technology Innovation Team Project No.IG201504N. The authors would also like to thank the anonymous reviewers whose comments greatly helped in making this paper better organized and more presentable.

\section{References}

1. V. A. Joshi, Titanium Alloys: An Atlas of Structures and Fracture Features (CRC Press, London, 2006)

2. Ezugwu E, Bonney J, Yamane Y., Journal of Materials Processing Technology 134, 3 (2003)

3. Rahman M, Wang Z-G, Wong Y-S, JSME Int J 49, 11 (2006)

4. Adilson Jose de Oliveira, Anselmo Eduardo Diniz, Davi Janini Ursolino., Journal of Materials Processing Technology 209, 6 (2009)

5. R Shetty, TK Jose, GD Revankar., International Journal of Current Engineering and Technology 4, 6 (2014)

6. Aouici H, Yallese MA, Chaoui K., Mabrouki T, Measurement 16, 3 (2012)

7. Bouacha K, Yallese MA, Khamel S., Belhadi S, Int J Refract Met Hard Mater 45, 6 (2014) 
8. DA Fadare, WF Sales, EO Ezugwu, J Bonney, Journal of Applied Sciences Research 16, 5 (2009)

9. SK Goyal, Vinayagamoorthy, International Journal of Current Research 36, 11 (2012)

10. ZQ Liu, AI Xing, LI TT, Y Wan, Journal of Shandong University 39, 6 (2009) 